Tables Annuelles Internationales de Constantes et Données numériques :

International Annual Tables of Constants and Numerical Data. 9 : Electromotive Forces, by Prof. H. S. Harned; Oxidation-Reduction Potentials, by G. Åkerlöf. Vols. 11-12 (1931-1936), Section 60. Pp. iii +45.25 francs. 13 : Faraday Effect, by M. Schérer; Magnetic Birefringence, Electric Birefringence, by Prof. A. Cotton and J. Rabinovitch ; Photoelectricity, by G. A. Boutry. Vols. 11-12 (Years 1931-1936), Sections 38-41. Pp. iii $+11+$ $12+7+10$. 20 francs. (Paris : Hermann et Cie.; New York: McGraw-Hill Book Co., Inc., 1937.)

$\mathrm{P}$ ARTS 9 and 13 of vols. 11-12 of "Tables Annuelles de Constants et Données Numériques" cover the period 1931-36. In Part 9, dealing with electromotive forces, H. S. Harned gives a convenient summary of data on concentration cells without liquid junctions, which will be very useful to workers in this field. Among the items of particular interest are Harned's own work on the thermodynamic dissociation constants of weak electrolytes, that of L. F. Nims on amino-acids, and several examples of ionic equilibria in heavy water. There is also a table of recently determined standard electrode potentials. This section should be used in conjunction with Part 3, in which the activity coefficients, free energies, etc., derived from the measurements, are given. G. Åkerlöf gives a summary of oxidation-reduction potentials, including the considerable number of organic systems, some of biological interest, investigated during the period.

Part 13 deals with the Faraday effect (M. Schérer), magnetic and electric birefringence (A. Cotton and J. Rabinovitch) and photoelectricity (G. A. Boutry). The latter, which is probably of the greatest general interest, contains a table of recent determinations of the photo-emission thresholds and work functions of metals. Since the elucidation of the theory of the photo-electric effect by Fowler in 1931, it has been possible to evaluate the true work function corresponding to absolute zero, and a considerable number of such determinations have now been made, which are collected here. Other sections deal with the effects of thin films of alkali metals and of complex films on the photo-emission, and there is also a summary of the characteristics of commercial photo-electric cells.

\section{Communication Engineering}

By Prof. W. L. Everitt. Second edition. Pp. $x+727$. (New York and London : McGraw-Hill Book Co. Ine., 1937.) $30 s$.

A $\mathrm{N}$ excuse for yet another text-book on the A electrical communication of information, that is, by electric wave-motion in space or along wires, is that it is a little better than its predecessors. This to a large extent is true of the present work, since the author's plan is attractive and the subject developed logically, as may be instanced by the general grouping of the chapters; these are classification of impedance elements, linear bilateral impedances, unilateral and non-linear impedances, coupling between electrical circuits and free space, and coupling between electrical and mechanical circuits.

The reader must not be put off by these and many other strange literary expressions; the subject is becoming so complicated that continual grouping of ideas is imperative. Nevertheless there is a number of prominent omissions, particularly as one is not warned of them; phase compensation, for example, should be included for students to-day, for it is as important as the degenerative amplifier, the properties of which are clearly stated. The most useful network theorems are grouped at the beginning, which does not indicate their relative importance, but apart from this the text can be well recommended.

L. E. C. H.

\section{The Analysis of Engineering Structures}

By Prof. A. J. S. Pippard and Prof. J. F. Baker. Pp. ix +554. (London: Edward Arnold and Co., 1936.) 30s. net.

7 HE final report of the Steel Structures Research Committee completed investigations of firstclass importance that have had great influence on the treatment of steel building frames. Both authors of this book were members of that Committee, and they are to be congratulated on so ably incorporating this recent work in a students' text-book on structural analysis. One chapter gives a valuable summary of the main findings and design methods, but elsewhere, as in the chapter on structural connexions, full use is made of the detail investigations of the Committee.

The book as a whole deals comprehensively with the principles on which structural design is based, and the work is carefully classified, wide in scope and-even apart from the work of the Research Committee-up to date, a fact which is shown by the chapter on mechanical methods of stress analysis, although it suffers somewhat from an undue brevity. The book is a notable addition to English text-books on structural analysis and in several respects marks new standards.

\section{The Truth about Vivisection}

By Sir Leonard Rogers. Pp. $x+182$. (London : J. and A. Churchill, Ltd., 1937.) 5s.

7 HE anti-vivisection campaign is persistent, vigorous and clamorous, has ample funds (estimated at $£ 40,000$ a year) with which to promote its objects, and uses a variety of methods to do so. It is the aim of Sir Leonard Rogers in this admirable little book to present the reader with the whole truth of the matter. He discusses the working of the Act of 1876 controlling and limiting experiments upon animals, analyses the reports of the Royal Commissions on Vivisection, and describes the valuable results that have been obtained through experiments upon animals in the curative and preventive treatment of diseases, both human and animal. It is a book that everyone should study who desires to ascertain the truth about vivisection, and will be most useful to those who may have to combat anti-vivisection propaganda.
R. T. H. 